\title{
Reporte de ocurrencia de lipidosis y timpanización en crías de cocodrilo de río (Crocodylus acutus) en cautiverio
}

\section{Carta al Editor}

\author{
Armando Rubio-Delgado ${ }^{1}$, Fabio G. Cupul-Magaña ${ }^{1}$, David Espinosa-Avilés²
}

${ }^{1}$ Departamento de Ciencias, Centro Universitario de la Costa, Universidad de Guadalajara. Puerto Vallarta, Jalisco. ${ }^{2}$ Departamento de Patología, Zoológico Guadalajara, Guadalajara, Jalisco.

Se documentan dos casos clínicos observados en ejemplares juveniles de cocodrilo de río (Crocodylus acutus) en cautiverio dentro de las instalaciones de la UMA "Reptilario Cipactli" de la Universidad de Guadalajara, campus Puerto Vallarta, Jalisco. Ambos organismos fueron capturados dentro del estero "Boca Negra", localizado en la porción norte de la ciudad de Puerto Vallarta.

El primer caso se registró en un individuo neonato de cinco semanas de edad (longitud total, $33.2 \mathrm{~cm}$; peso, $90.4 \mathrm{~g}$; marcado con el número 242), que se descubrió muerto dentro del estanque de un acuaterrario de experimentación dietética. La necropsia se realizó aproximadamente 10 horas después del deceso y reveló que el tejido muscular, en general, se encontraba cianótico y las mucosas ictéricas; las únicas anormalidades evidentes en órganos fueron un hígado intensamente ictérico, y una ligera hemorragia periférica en el corazón. El estudio histopatológico del corazón reveló leve infiltración mononuclear difusa, algunos miocitos atrofiados, y un área de necrosis media y hemorragia. En el hígado se observó una moderada degeneración vacuolar de hepatocitos, y necrosis difusa ocasional, además, en algunas zonas se detectó vasculitis leve. Un corte del hígado presentó severa y difusa distensión de hepatocitos por vacuolas lipídicas. En el análisis del pulmón se observó congestión y fibrina en espacios aéreos, en algunas áreas el intersticio se encontró infiltrado por histiocitos, además, un vaso sanguíneo mostró degeneración con mínima inflamación. En el páncreas se detectó necrosis marcada, y una moderada a severa infiltración multifocal extensiva de linfocitos e histiocitos, con escasos heterófilos, se observaron bacilos bacterianos asociados a las lesiones.

Lo anterior permitió establecer como causa del deceso una pancreatitis subaguda y lipidosis

Solicitud de sobretiros: M. en C. Fabio G. Cupul-Magaña. Depto. de Ciencias, Centro Universitario de la Costa, Universidad de Guadalajara, Av. Universidad de Guadalajara No. 203, Delegación Ixtapa, C.P. 48280, Puerto Vallarta, Jalisco, México. 


\section{A Rubio-Delgado, FG Cupul-Magaña, D Espinosa-Avilés.}

hepática severa.

La lipidosis hepática es la excesiva acumulación de lípidos en forma de vacuolas en el citoplasma de los hepaticotos. Es un proceso fisiológico-patológico complejo que puede deberse a diversos factores, entre ellos inanición, mala absorción, dieta inadecuada con exceso de ácidos grasos poliinsaturados y, raramente, una disfunción metabólica, ya sea hepática o pancreática. Una moderada acumulación de vacuolas de grasa en diversos órganos, principalmente hígado, es común en diversas especies, y aún en casos relativamente severos no siempre se asocia a disfunción y enfermedad. Sin embargo, la palidez y el grado de lipidosis del hígado este caso fueron considerablemente mayores a lo que se observa en cocodrilos de esta edad. En cocodrilos la lipidosis hepática se desarrolla rápidamente, siendo una de sus principales causas la inanición producida por estrés continuo, por la competencia con sus congéneres, o por residir en un hábitat inadecuado (1-4).

Consideramos que en este caso es muy probable que la lipidosis hepática fuera un proceso secundario a la pancreatitis, aparentemente bacteriana (bacilos Gram negativos), esto debido a la severidad de las lesiones y a que una disfunción pancreática afecta el metabolismo de las grasas, pudiendo generar como consecuencia lipidosis hepática. Otra posibilidad es que existiera primero una disfunción hepática y se haya desarrollado una infección secundaria posteriormente. El ejemplar en cuestión fue capturado cuando contaba con una semana de vida y, desde su ingreso al acuaterrario, se le detectó un bajo volumen en biomasa (en comparación con los de su camada), lo que podría ser evidencia de que este ejemplar ya presentaba un proceso de infección o disfunción. El animal fue capturado en su hábitat natural el 18 de julio de 2001 y murió el 14 de agosto del mismo año.

El segundo caso correspondió a un cocodrilo neonato de nueve semanas de edad (longitud total del cuerpo, $33.7 \mathrm{~cm}$; peso, $100 \mathrm{~g}$; marcado con el número 222), que se encontró muerto dentro del estanque de un acuaterrario de experimentación dietética. La mayoría de las 25 crías que compartían el estanque con el ejemplar muerto presentaron un cuadro de timpanización a las 24 horas posteriores del suministro de su ración alimenticia; asimismo, una cría se encontró en estado de salud delicado, por lo que inmediatamente se le realizó lavado y extracción del contenido gástrico y se le administró Metamizol sódico I.M. $5 \mathrm{mg} / \mathrm{kg}$, con lo que presentó mejoría a los pocos minutos de realizado el tratamiento. Actualmente goza de buena salud. Al ejemplar muerto se le practicó la necropsia. Se observaron todos los tejidos con apariencia normal, líquido transparente en cavidad celómica, los intestinos con poco contenido alimenticio y con gran cantidad de gases, el estómago con gastrolitos ( $5 \mathrm{~g})$ y contenido alimenticio sin digerir.

El principal hallazgo histopatológico fue congestión moderada a severa en pulmón, corazón, hígado, intestino, bazo y riñón. Adicionalmente, en el riñón se observó necrosis isquémica moderada a severa del epitelio tubular. El hígado con una leve degeneración de hepatocitos. Pulmones con necrosis ocasional del epitelio respiratorio e inflamación mononuclear leve. En el corazón necrosis ocasional de algunos miocitos. El intestino presentó inflamación moderada heterofílica de la mucosa.

El diagnóstico morfológico de este caso fue congestión generalizada severa, necrosis renal isquémica moderada, y enteritis heterofílica moderada. La causa de la muerte fue una éstasis vascular (choque) e hipoxia, producidos por la formación de gas por el material alimenticio, lo que provocó timpanismo (5-7).

La revisión de los elementos contenidos en el suplemento adicionado al alimento a base de pescado, aportó información sobre lo que produjo el timpanismo en los cocodrilos. Se encontró que la presentación comercial del calcio granulado utilizado como suplemento contiene magnesio, mismo que al entrar en contacto con la solución de Dextrosa al $5 \%$ (también componente de la dieta) causa efervescencia. En el suplemento

\section{Revista Biomédica}


alimenticio normalmente se usa como aglutinante un hemolizado de sangre de res, que se mezcla con todos los ingredientes de la dieta experimental y evita la efervescencia. Sin embargo, por fallas en el manejo un día antes de la muerte de los ejemplares, al momento de presentarles el alimento a los cocodrilos se le adicionó al pescado los suplementos espolvoreados sin aglutinante, lo que provocó una gran producción de gases, con lo que se generó el cuadro de timpanización. La presión generada por el gas produjo incoordinación y ataxia de extremidades posteriores por la opresión de nervios en la cavidad celómica; asimismo provocó compresión de órganos, éstasis vascular, hipoxia y la muerte. El animal fue capturado en su hábitat natural el 18 de julio de 2001 y murió el 12 de septiembre del mismo año.

Este reporte ejemplifica que la base para el desarrollo adecuado de los organismos en cautiverio, es la supervisión continua de su comportamiento y de los elementos incluidos dentro de su dieta, aspectos relevantes en el manejo de la fauna silvestre.

Palabras clave: Crocodylus acutus, lipidosis, timpanización.

\section{REFERENCIAS.}

1.- Dimski DS, Taboada J. Feline idiopatic hepatic lipidosis. Vet Clin North Am Small Anim Pract 1995; 25:357-73.

2.- Frye FL. Pathology. En: Biomedical and surgical aspects of captive reptile Husbandry. Veterinary Medicine. Edwardsville: Publishing Co; 1981. p. 373-446.

3.- Frye FL. Nutritional disorders in reptiles. En: Hoff GL, Frye FL, Jacobson, ER. editores. Diseases of Amphibians and Reptiles. New York: Plenum Press; 1984. p. 633-60.

4.- Jones TC, Hunt RD, King NW. Veterinary Pathology. 6th ed. Baltimore: Williams \& Wilkins; 1997.

5.- Jubb KV, Kennedy PC, Palmer P. The alimentary system. En: Pathology of domestic animals. 4th ed. Orlando: Academic Press; 1992.

6.- Larsen RE, Buergelt C, Cardeilhac PT, Jacobson ER. Steatitis and fat necrosis in captive alligators. J Am Vet Med A 1983; 183: 1202-4. 